\title{
Student Teachers' Changes in Perspective on Education News Reports: A Framework for Reading, Dialogue, and Reflection on Education News
}

\author{
Shih-Hsiung Liu ${ }^{1}$ \\ ${ }^{1}$ Center for Teacher Education, National Changhua University of Education, Taiwan \\ Correspondence: Shih-Hsiung Liu, Center for Teacher Education, National Changhua University of Education, \\ No.1, Jin-De Road, Changhua, Taiwan. Tel: 886-4723-2105. E-mail: shsiung@cc.ncue.edu.tw
}

Received: May 28, 2014 Accepted: July 4, 2014 Online Published: August 14, 2014

doi:10.5539/ies.v7n9p39 URL: http://dx.doi.org/10.5539/ies.v7n9p39

\begin{abstract}
This study examines the changing perspectives of Taiwanese student teachers toward the news coverage of educational events by proposing a framework of reading, dialogue, and reflection on education-related news report. In this study, we enrolled 28 student teachers to participate in the framework, being practiced seven times. To validate the analytical results, we obtained primary research data by using a designed worksheet, dialogue observation, individual notebooks, and interviews. The analytic results show that the previous experiences of student teachers influenced they form perspectives on reported events, thereby facilitating in-group dialogue. Peers who express experiences similar to those reported in the events influence the perspectives of other participants by causing two types of changes: (a) alternative thoughts: expressing alternative opinions for confronting conflict; and (b) deepening thoughts: re-examining the conflict through reflection, and expressing a method of resolving conflicts by projecting personal experiences. The proposed framework can provide teacher educators with a curriculum program that encourages student teachers to broaden their awareness of biased news coverage of education, and to enhance their comprehension of educational practices.
\end{abstract}

Keywords: student teachers, teacher education, reading, reflection, education news

\section{Introduction}

Previous research has asserted that reading newspapers is a method of self-study for teachers (van Eekelen, Boshuizen, \& Vermunt, 2005); however, few studies have addressed how news coverage of education affects the opinions of student teachers, and particularly whether negative educational news stories cause student teachers to generate negative stereotypes toward education. In a previous study, the author employed an experimental research method involving a two-group pretest posttest design, and determined that subjective or biased educational news stories negatively affect the education-related beliefs of student teachers (Liu \& Tsao, 2013). Student teachers primarily rely on a limited number of metacognitive strategies and engage in reading behavior that ranges from skimming and incomplete reading practices to not reading at all (Lesley, Watson, \& Elliot, 2007), potentially affecting their reading comprehension (Akyol \& Ulusoy, 2010); thus, teacher educators should train student teachers to rationally approach a wide range of news topics.

In Taiwan, the sociocultural context of various ideologies differs from that of the ideologies used in Western societies; this affects the opinions of Taiwanese people and arguments on social topics. Ideological differences are reflected in news coverage; by applying distinct headline topics, editing, and linguistic structures, newspapers can each present disparate representations of a single event (Nakamura, 2004). Taiwanese public schools are typically characterized by extensive testing, lecture-type instruction, and strict discipline and the student of such schools are not encouraged to think critically or reflectively (Liu, 2011; McBride, Xiang, Wittenburg, \& Shen, 2002); thus, Taiwanese students may evaluate the value of information based on a single source. In other words, a lack of reflective thinking when reading biased educational news stories may cause inadequate comprehension of the reported events. $\mathrm{Lu}$ (2010) indicated that most Taiwanese news coverage on education tends to address the shortcomings of the education field. In my previous study (Liu \& Tsao, 2013), the authors suggested that subjective or biased educational news stories negatively affect the beliefs of pre-service teachers; however, few studies have explored the reflections of Taiwanese students after reading 
education-related news.

Theoretically, if Taiwanese student teachers frequently read biased news coverage of education, their pedagogical perspectives may change; this could further modify their perceptions of and ideals regarding teaching. Thus, it is necessary to facilitate student teachers' reflections on reading, especially considering that the majority of students have not been taught how to be self-reflective in higher education (Rabikowska, 2008). An approach to encouraging students to reflect is through dialogue, which would allow them to articulate their developing ideas, to receive feedback, to reread all records, and to then respond to how their reflections over time (McMahon, 1997).

Based on social interaction theory (Brown \& Renshaw, 2000; Vygotsky, 1978), which supports the progressive development of understanding, this study proposes a framework for reading affordances of education news coverage in the context of teacher education. Specifically, the purpose of this study is to examine the changing perspectives of student teachers toward the news coverage of educational events.

\section{Literature Review}

\subsection{News Coverage on Education}

News writing is often described as an inverted pyramid (McKane, 2006). The first paragraph of a news story is called the lead. A lead informs readers of the main story, or it attempts to "hook" the attention of readers. The subsequent paragraphs detail the sequence of events to provide readers with a thorough understanding of the story. The appropriate usage of text in news stories (i.e., appropriate title, clear sentence structure, and correct punctuation) is essential to ensure that the news is persuasive and that it encourages readers to continue reading. However, the content of certain news reports conflict with the headlines; as such, headlines might convey an ideology that is relatively unrelated with the actual report that draws the attention of readers (Oroujlou, 2012). The word choice of a headline and any biased content potentially influence a reader's perspective on the event being reported.

A substantial volume of media literature has addressed the nature and extent of this influence on audience perception, opinion, and behavior (Anderson, 1997; Devereux, 2003; Gregory \& Miller, 1998; Keeble, 2001; Ross \& Nightingale, 2003). Research has shown how samples in news articles significantly affect the perceptions and judgments of readers about issues (Cheng, Hawton, Lee, \& Chen, 2007; Kim et al., 2012; Zillmann \& Brosius, 2000). The news media affect how people perceive the salient issues of the day (McCombs \& Reynolds, 2002).

Education news encompasses any news coverage reporting on education-related events or concerns such as education policy institutions, individual schools, administrators, teachers, students (Clark, Brass, Rowe, \& Menzies, 2003), or parents. Educators pay close attention to education news, and occasionally discuss such reports in general conversation with others. For example, Wade and Yarbrough (1996) requested that student teachers create portfolios to document their learning and growth, and they noted that the student teachers frequently cited, as a topic of reflection, newspaper articles discussing national issues that affect seniors.

The news media often sensationalizes events, and portrays them as a general reflection of social disruption and moral decline (MacMill, 2002). However, many highly exaggerated issues are emotionalized by the media. According to Lu (2010), local news among Taiwan's four national newspapers primarily reported arson, criminal activities, disasters, and scandals. This coverage has generated negative stereotypes in Taiwanese society. Taiwanese student teachers frequently encounter negative education reports from the media.

Education news provides a valuable contribution to readers' understanding of national education. However, education news coverage that presents a negative ideology is harmful for student teachers because they lack sufficient experience and knowledge in evaluating these reports in a realistic context. Student teachers may encounter challenges when increasing their general awareness regarding their future careers, and may attempt to acquire a deep understanding of particular educational events.

\subsection{Dialogue and Reflection for Knowledge Development}

Partner story reading activity provides an opportunity for peer social dialogue (Dixon-Krauss, 1995) and the dialogue provides an opportunity for people to communicate and to explore both individual and collective presuppositions, ideas, and feelings that subtly influence their interactions (Bohm, Factor, \& Garrett, 1991). Furthermore, many studies have shown that dialogue facilitates self-reflection (Crasborn, Hennissen, Brouwer, Korthagen, \& Bergen, 2011), as well as the evaluation and integration of knowledge (Hermann \& Woyach, 1994); furthermore, reflection on the content of dialogue can improve a person's information awareness (Albrechtsen \& Hovden, 2010; Ekşi, 2013). Researchers have also indicated that dialogue encourages student teachers to 
demonstrate broad differences in coping with controversial topics (McMahon, 1997) and that collaborative peer reflection facilitates developing their professional knowledge (Manouchehri, 2002). When student teachers interpret and practice reflection in a teacher preparation program, they can possess a general understanding of reflection through constant evaluation, and learn to reflect through various opportunities in different contexts (Pedro, 2005).

Dialogue and reflection are considered the critical factors in a "meaning making" process. Theoretically, reflective processes may lead to professional growth through a developmental process referred to as internalization, which involves the critical assessment of existing perspectives (Gillespie, 2007). Self-reflection arises "through internalizing the perspective that the other has upon self, followed by self taking the perspective of other upon self" (Gillespie, 2007, p. 682). Facilitating dialogue, interaction, and reflection is critical when multiple perspectives nurture and shape knowledge production. In educational settings, peer dialogue and discussion play a critical role in promoting learning abilities and facilitating knowledge development; when peers share knowledge, the information can be criticized or elaborated on by a partner (Postholm, 2008).

Moreover, self-reflection during reading involves a person's early experiences (O'Callaghan, 2001). Okan and Yildırım (2004) indicated that student teachers referred to their early experiences when reflecting during practice. In addition, peer dialogue and self-reflection can facilitate changes in the perceptions of student teachers, regardless of their views or cognitive processes. Through discussion, the social construction of knowledge provides opportunities for student teachers to engage in self-reflective practices, explore learning tasks (Stump, 2010), and change their way of thinking by sharing mutual ideas and experiences (Rushton, 2003). According to Tal (2010), student teachers claimed that discussion methods substantially contributed to their learning, and altered how they processed their reflections. Thus, reading, dialogue, and reflection appear to be the elements of the integrative process that enable student teachers to comprehend information and extend their thinking, and these elements particularly affect the comprehension of biased news stories.

Reported educational news stories differ from typical articles because they can imply the ideology of the reporter. When education news coverage is biased, the perspectives of student teachers toward the reported education events may be affected because they lack sufficient background knowledge, potentially causing them to develop inadequate educational values. Moreover, because reading educational news stories involves individual experiences, it can facilitate peer dialogue and reflection and expand the initial perspectives of the readers. We anticipate that the proposed framework provides Taiwanese student teachers with alternative perspectives through the process of internalization, which involves information processing (reading), comparisons between different perspectives (dialogue and reflection), and changes to their initial perspectives.

Because the proposed framework may change the perspectives of student teachers in reported educational events, the following research questions were addressed: What influenced the perspectives of the student teachers on the news coverage of educational events? What types of change did the student teachers show in the perspectives toward educational events after participating in the activities of reading, dialogue, and reflection?

\section{Research Methodology}

The above literature reveals that reading activities provide an opportunity for dialogue, and the dialogue further facilitates self-reflection. Moreover, self-reflection improves a person's information awareness and may be a professionally fruitful way of effecting belief change (Tillema, 2000). To advance current understanding of changes in perspective on education news reports for student teachers, a framework for reading, dialogue and reflection was developed to examine effectiveness of change. Moreover, the evaluation data should be collected from observations, interviews and records in the processes of the framework and are employed to make sense of the participants' performances in terms of the meanings participants bring to them, based on the perspectives of Denzin and Lincoln (2013) on qualitative research. Thus, qualitative research methods were used in this study.

\subsection{Framework for Reading, Dialogue, and Reflection}

The proposed framework is based on Vygotsky's theory of social interaction (Brown \& Renshaw, 2000; Vygotsky, 1978), and provides student teachers with a work space for small group and peer interaction. The framework comprises the following four phases.

First, each participant was requested to read a selected education news report. Afterward, participants were required to describe the event in writing in the first column of a structured worksheet. The description was used to confirm effective reading on education news. The participants completed the work in $10 \mathrm{~min}$.

Second, all participants were requested to comment on the reported event and to write their comments in the second column of the worksheet in $5 \mathrm{~min}$. 
Third, each group (randomly assigning 4 to 5 participants to a group) took turns sharing their comments through dialogue. The grouping provided each participant with additional opportunities to interact with others individually in an inter-group context rather than to compare comments among the groups. While each participant presented his or her comment, the other participants wrote the name of the presenter and the statement in their own notebook. This task provided each participant with additional material for consideration, evaluation, and reflection. The phase was completed in $20 \mathrm{~min}$.

Finally, all participants reflected on their own comments and those of the other participants. Subsequently, all participants wrote their own final perspectives about the event in the third column of the worksheet. This was completed in less than $10 \mathrm{~min}$.

\subsection{Participants}

A total of 54 universities with teacher education institutions in Taiwan prepare their students for k-12 teachers. To obtain transferability, we purposively invited student teachers enrolled in a sampled teacher education institution in the middle area of Taiwan to participate in this study, and 28 student teachers (aged 20-23 years, 10 male and 18 female) participated in this study. The participants were randomly assigned to one of six groups. Prior to practices, all participants were instructed on how to implement and complete the work for each phase of the proposed framework. The framework was practiced seven times from March to April of 2013 (one session per week).

\subsection{Educational News Stories}

Fourteen education news articles were initially selected from the four main newspapers in Taiwan. The articles were selected by five experts in teacher education and 30 student teachers based on the following two criteria: (a) the articles induced strong perceptions; and (b) the articles promoted discussion. Based on their responses, seven educational news stories were selected for this study. Each news story was approximately 600 words in length.

Take two pieces of educational news stories as examples, in which participants' descriptions of the two news articles were intentionally cited to clarify the analytical results in this study: (a) "A junior high school student frolicked and brawled during teaching. The teacher restrained the student's behavior but was verbally abused by the student. The teacher angrily slapped the student across the face. The parent of that student subsequently accused the teacher of using physical punishment. The teacher might be laid off because her profession was evaluated as disqualified"; and (b) "A copy of the math examination paper shows a question with the description, 'By selecting the correct answer, you can gain two points. If you do not know the answer, please tick "I do not know the answer" and then you can get one point for the question.' The teacher expressed later in an interview that he wants to foster students' honesty. However, the most diligent students and their parents doubted the purpose of this exam." The first news story did not allude to the inappropriate behavior of the student, implying that the teacher took full responsibility for the event. The reporter in second story neglected the teaching autonomy of the teacher, and inferred that inappropriate methods were being used based on the doubts of the parents and the students. Both of these news stories are considered examples of biased reports.

\subsection{Data Collection}

To achieve dependability, being demonstrated by the use of overlapping methods, and validate the analytical results, we obtained primary research data by using a designed worksheet, dialogue observation, individual notebooks, and interviews. Each participant was asked to provide at least one description or comment in each column of the worksheet by using the criteria of Hatton and Smith (1995), i.e., descriptive, descriptive reflection, dialogic reflection, and critical reflection, to assess the quality of reflection and change. The participants were also asked to record the comments of each participant in their notebooks.

During group discussions, the participants took turns engaging in dialogue. The researcher observed and recorded this dialogue, including how frequently they participated and which conditions affected their comments.

After completing the process, all data were analyzed immediately. We compared the initial and final perspectives that all participants recorded on their worksheets, and referred to each of their notebooks. The researcher interviewed the participants who had exhibited the most and least amount of change in their perspective following each reading activity.

The interviewees were asked the following questions: (a) How did you arrive at your perspective while reading the news article on an educational event? (b) During the dialogue activity, did the other participants influence your opinion about the educational event? (c) Why did you (not) change your perspective? and (d) Who or what influenced you? 


\subsection{Data Analysis}

Data analysis utilized a process of constant comparison for recurring words and emerging patterns. (Lincoln \& Guba, 1985). The trustworthiness of the analysis process was maintained using the four-part framework of credibility, transferability, dependability and confirmability (Lincoln \& Guba, 1985). In addition to transferability mentioned in Participants section and dependability mentioned in Data Collection section, confirmability and credibility involve carefully cross-checking multiple data.

To obtain confirmability, three trained researchers independently reviewed each participant's initial and final perspectives and compared these observations with the records in each notebook to confirm which factors had influenced the changes (if any) in the participants' perspectives. Subsequently, they met to reach consensus on the changes in perspectives of participants.

For the interview data analysis, we reviewed the transcripts to identify the participants' self-reflection on individual perspectives, regardless of the nature of that change. After transcribing the interviews, we categorized the participants' descriptions as a set of key themes related to their reading methods, individual experiences, peer dialogue, and changes to their perspectives. When a pattern of behavior was identified, we reviewed the findings to identify any patterns, relationships, and trends among the data. We triangulated the reliability of the data analysis for achieving credibility and further identified why the participants changed their initial perspectives.

\section{Results}

The three patterns that emerged during data analysis indicated the following: (a) the early experiences of the participants influenced how they responded to the reading thereby facilitating in-group dialogue; (b) their commentary, including examples from previous experiences, influenced others during the dialogue; and (c) they were introspective while evaluating the perspectives of other participants.

\subsection{Influence of Previous Experiences on the Participants' Reading Activities}

When quickly reading a headline and news story, the student teachers were influenced by their previous experiences that were relevant to the reported education event, and their perspectives developed further throughout the process. Based on the observation data, the majority of participants did not literally read the news stories. The first interviewee stated the following:

The headline and first paragraph of the news story attracted my attention, but the rest of the story was rough in my memory. I did not read the education news the way I would read a textbook. Instead, I generally skimmed the newspaper (ST04, March 15, 2013).

The researcher transformed this method of reading into an additional interview question, and identified most participants employed the method when reading the news articles. Moreover, seven interviewees expressed that their relevant junior and senior high school experiences guided their comprehension of the news stories and facilitated their participation in the dialogue.

To comprehend the article, I tried to imagine a realistic situation based on my memory of high school...because previous experiences were aroused, my classmates constantly told stories about high school (ST07, March 22, 2013).

The news article stated that a teacher awarded extra scores to the students who responded "I don't know the answer" in an examination. My junior school teacher also used this method to foster our honesty. Nevertheless, my teacher's methods differed from those of the teacher in the news story. I talked a lot about my teacher's strategies to my classmates (ST17, April 20, 2013).

This study analyzes participants' comments on the worksheet and reveals that some student teachers supported the reported teacher's behavior about supplying extra scores, whereas others disagreed. A comparison of data from worksheets, dialogue observations, and interviews indicated that the previous experiences of the student teachers provided several bases of reference when reading the news articles. However, the comments on the reported events varied because of differences among their previous experiences. According to the interview results, the reading activities prompted student teachers to recall their experiences, thereby facilitating dialogue.

\subsection{Commentary with Examples from Early Experiences Influenced Other Participants during Dialogue}

Although the participants' individual experiences influenced their reading of the articles, not everyone shared their experiences during the dialogue activity.

By analyzing the worksheets and dialogue observations, and subsequently comparing the participants' change in perspective on the examined news articles, approximately one or two participants for each reading activity did 
not change their perspectives. Those participants specifically clarified their previous experiences related to the articles during the dialogue activity. Moreover, a review of their notebooks showed that the notes on the comments of other participants were different, which verified that their final perspectives on the news reports were dissimilar to those of the other participants. This study shows that those who gave their comments with examples from early experiences were not influenced by the dialogue activities.

The participants who gave their comments with examples from early experiences further influenced the perspectives of others. As discussed, the participants whose perspective remained unchanged presented their view by describing their experiences to the group. Conversely, although the previous experiences of participants were considered an element of the reading activity, the participants who had changed their initial perspective did not express their previous experiences in either the dialogue activity or their notebooks. Moreover, after comparing the final perspectives of the affected participants and their notebooks, we identified that the majority of their final perspectives were similar to the comments made by the participants whose perspectives were unchanged. However, because the previous experiences differed among the participants, it was not the same group of participants whose perspectives were unchanged for all seven articles.

A participant with both unchanged and changed initial perspectives expressed the following during the interview:

In my opinion, the teacher reported in the article would not be laid off, despite physically punishing the student. It is very difficult to lay off a teacher based on relevant laws in Taiwan. In my previous school, teachers who had exhibited similar conduct are still working ...(ST15, March 22, 2013).

The participant was subsequently questioned on whether his or her perspective had been influenced during the dialogue activities, and responded with the following:

No, my classmate's opinion convinced me in final dialogue activity. I think that she had experienced an event similar to the one we discussed (ST09, March 29, 2013).

Thus, the participants who expressed early experiences during the dialogue activities influenced the perspectives of the other participants. Thus, commentary based on examples from early experiences during dialogue is a key factor in changing the perspectives of others.

\subsection{Influence of Self-Reflection on Changes in Perspective during the Dialogue Activities}

Analyzing the worksheets indicated that following the dialogue activities, approximately $80 \%$ of participants changed their initial perspectives on the examined articles regardless of whether they expressed alternative or deepening thoughts. For example, regarding the article about the student who was punished by his teacher, one participant recommended applying administrative procedures to the student who had committed the offense, and expressed concern for the teacher's rights, which contrasted with the participant's initial perspective on the teacher's inappropriate behavior. One participant expressed that the teacher should not slap students, but rather, should play a counselor role in the classroom; this exhibited deep thinking in contrast to the initial comment that indicated both had done wrong. By constantly comparing and categorizing all of the worksheets, the analytical results show that the alternative opinion appears to relate to how conflict should be addressed in such an event, whereas the participants' deepening thoughts referred to identifying the cause of the conflict and to promoting the most suitable approach to resolving it.

The participants' change referred to their reflections after comparing their own opinions with those of the other participants. According to previous literature (Hermann et al., 1994; Okan \& Yıldırım, 2004), reflection is involved in individual evaluation processes. In other words, evaluation is similar to a tool for reflection. This study interviewed participants whose perspectives had changed, and shows that an evaluation occurred when the perspectives of other participants differed from their own. One participant stated the following:

Sometimes I agreed with others' opinions on educational events. I basically evaluated the appropriateness of those opinions. There are a few innovative perspectives that I did not consider in the initial phrase. I will accept them when they are appropriate (ST11, April 6, 2013).

Moreover, after analyzing and comparing the participants' worksheets and notebook, this study confirms that an evaluation and a reflection facilitate changes in the perceptions of student teachers.

This study further examined how the two types of changes differed throughout the process. By comparing the dialogue observation, interview, and worksheet data, this study shows that self-projection is a key factor. The worksheet of a participant who exhibited deepening thoughts expressed the following reflection:

The reported teacher cannot punish the student. However, the student should not abuse the teacher. (initial perspective, ST22, April 12, 2013) 
When addressing teacher-student conflicts, if I were the reported teacher, I might be concerned about the student's emotions, and attempt to understand what is wrong with the student. (final perspective, ST22, April 12, 2013)

Regarding the changed participants who had alternative thoughts, the meaning of the descriptions of peers was the primary recourse when evaluating various comments. Two changed participants were interviewed, and they responded as follows:

Regarding the teacher who punished the student, I think that the comment proposed by classmate B-2 was reasonable because school regulations should be followed (ST19, March 29, 2013).

Regardless of what happens, I agree that the teacher should not punish student. However, the news coverage favored the student. A teacher should have basic human rights (ST08, April 6, 2013).

These descriptions were written in their notebooks. This participant assimilated the description of the other participant rather than considering how he or she would react if he or she were to be involved in the discussed event, whereas the participants who exhibited responses that were more reflective frequently used statements such as "If I were..." Moreover, approximately $80 \%$ of participants whose perspectives had changed appeared to assimilate the descriptions of others. The remaining participants exhibited a characteristic of self-projection to promote what they purported to be adequate methods for resolving the conflict. Assimilation and self-projection during dialogue might result in the two changes in perspective, supplying alternative opinions and promoting methods of resolving conflicts.

As discussed, the analytical results show that the majority of student teachers changed their initial perspectives, regardless of whether they expressed an alternative thought or developed a deepening thought. The perspectives of the student teachers who participated in this study changed because of the dialogue activities. Although previous literature (Crasborn et al., 2011; McMahon, 1997) has shown that peer dialogue can extend the perspectives of student teachers, the findings in this study further indicate that both sharing previous experiences and self-reflection causes two types of change through alternative thoughts and deepening thoughts. The two types of changes differed by either assimilating the expressed opinions of others during the dialogue activities or by the participants considering how they would react if the discussed events were to occur to them.

\section{Conclusion and Discussion}

In this study, a framework was proposed for the education-related reading, dialogue, and reflection of student teachers. The previous experiences of student teachers influence how they form perspectives on reported events. In addition, activities that involve reading educational news stories can prompt student teachers to recall their experiences, thereby facilitating in-group dialogue. Finally, most student teachers changed their initial perspectives. Peers who express experiences that are similar to those reported in the examined events influence the participants' perspectives in two types of changes, alternative thoughts and deepening thoughts. The two types of change to the participants' perspectives on the reported events resulted from comparing the expressed opinions of others during the dialogue activities by either assimilation or self-projection.

As discussed, the student teachers in this study quickly read the news articles and formed their initial perspectives on the reported events based on their previous experiences. Compared with previous literature (Cheng, Hawton, Lee, \& Chen, 2007; Kim, Bigman, Leader, Lerman, \& Cappella, 2012; Zillmann \& Brosius, 2000) that indicated that the bias of news reporters potentially influences the judgments of readers, this study asserts that the previous experiences of student teachers is a key factor influencing their perspectives on reported events, similar to the findings by McMahon (1997). In other words, although news coverage is frequently criticized as being subjective or biased, which results in difficulty comprehending education news, whether student teachers are influenced by subjective coverage depends on their previous experiences (i.e., at junior and senior high school). Nevertheless, because student teachers in Taiwan lack reflective abilities and sufficient practical teaching experiences, their perceptions regarding reported events should be noticed when they read education-related news.

Furthermore, during this study, early experiences were involved in the formation of participants' perspectives on education news, which may also impact the opinions of others through dialogue and reflection. As reported in extant literature (Crasborn et al., 2011; Hermann et al., 1994; McMahon, 1997; O'Callaghan, 2001; Okan \& Y1ldırım, 2004), dialogue, involving the exchanges of ideas, can facilitate individual reflection, evaluation, and the integration of knowledge in the field of reading.

Rushton (2003) and Stump (2010) demonstrated that peer dialogue involving reflection both extends the perspectives of student teachers and changes their thinking concerning education-related news. The participating 
student teachers were asked to express themselves and to respond to the comments of others. During these activities, they compared their comments, assimilated appropriate opinions, and projected their own experiences. Subsequently, they changed their initial perspectives by expressing alternative opinions and engaging in introspection. This finding is similar to the argument of Gillespie, (2007), who addressed that self-reflection lead to knowledge growth through internalization, and the critical assessment of existing perspectives. The participating student teachers yielded the following two categories of change: (a) expressing alternative opinions for confronting conflict; and (b) re-examining the conflict through reflection, and expressing a method of resolving conflicts by projecting personal experiences. Peer dialogue that facilitates changes in student teachers' perspective has been explained by Manouchehri (2002), who indicated that once a person is placed in a situation where he or she must explain the choice of pedagogy and practice, a greater understanding of the issues associated with learning and teaching may become apparent.

Additionally, the model of self-reflection should be adopted and taught in teacher education courses. Although educational news story is an occasional case of educational event, it provides teacher educators with a material for educational practice. However, news stories, differing from well-designed case by tutor, involve incomplete description with a biased ideology. Engaging in dialogue with peers who have extensive experience, as well as self-reflection through a process of comparing, revising, student teachers may discover the potential meaning of news stories. Through reading, dialogue and reflection of education news, student teachers can extend their knowledge in teacher education courses, and extend initial perspectives on education events. Furthermore, they can construct their own understanding on educational practices.

Today, self-reflection should be a mandatory element in teacher education program because it has increasingly become a key element of effective teacher professional development. However, as previously mentioned, education in Taiwan typically involves lecture-based learning and does not focus on critical thinking (Liu, 2011; McBride, Xiang, Wittenburg, \& Shen, 2002). Moreover, Taiwanese news coverage on education-related events typically presents biased or subjective perspectives. When student teachers frequently read negative education-related news stories, it can diminish their enthusiasm toward education. If the educational situations and mass-media cultures of other countries (e.g., those in the Middle East, Africa, Latin America, or large parts of Asia) are similar to those in Taiwan, student teachers could be trained using the proposed framework, which involves materials related to education news.

Previous studies have indicated that dialogue-based reflection enables student teachers to articulate their ideas, receive feedback, reread their records, and subsequently respond to how their reflections have changed over time (McMahon, 1997). The current findings indicated that reading educational news stories prompted student teachers to recall their experiences, thereby facilitating dialogue with others; this contributes to the literature by developing a framework for reading, engaging in dialogue, and reflecting on education news, and identifies the feasibility of the framework for student teachers. Furthermore, the proposed framework can provide teacher educators with a training program that encourages student teachers to broaden their awareness of biased or subjective news coverage of education through comparing the expressed opinions of others by either assimilation or self-projection, and to enhance their comprehension of educational practices. The findings in this study show that student teachers present two categories as examples for change in perspective through reflection. Future research can examine the effects of these two types of changes when addressing general education problems. Moreover, in this study, the participants were not taught the skills of reflection. It is unclear whether the influence of other participants would have been different if the participants in this study possessed well-developed skills in reflection on education news. According to the literature, instruction on self-reflection may allow people to form deeper perspectives. It is reasonable to assume that the findings in this study, indicating that most participants changed their perspectives by assimilating the descriptions of other participants, may have been different if the participants had been taught various self-reflection skills.

\section{Acknowledgements}

The research is financed by National Science Council of the Republic of China, Taiwan. No. NSC-102-2410-H-018-003-.

\section{References}

Akyol, H., \& Ulusoy, M. (2010). Student teachers' use of reading strategies in their own readings and future classrooms. Teaching and Teacher Education, 26(4), 878-884. http://dx.doi.org/10.1016/j.tate.2009.10.026

Albrechtsen, E., \& Hovden, J. (2010). Improving information security awareness and behaviour through dialogue, participation and collective reflection. An intervention study. Computers \& Security, 29(4), 432-445. http://dx.doi.org/10.1016/j.cose.2009.12.005 
Anderson, A. (1997). Media, culture and the environment. London: UCL Press.

Bohm, D., Factor, D., \& Garrett, P. (1991). Dialogue-A proposal. Retrieved from http://www.david-bohm.net/dialogue/dialogue_proposal.html

Brown, R. A. J., \& Renshaw, P. D. (2000). Collective argumentation: A sociocultural approach to reframing classroom teaching and learning. In H. Cowie, \& G. Aalswoort (Eds), Social interaction in learning and instruction: The meaning of discourse for the construction of knowledge (pp. 52-66). Amsterdam: Pergamon.

Cheng, A. T., Hawton, K., Lee, C. T., \& Chen, T. H. (2007). The influence of media reporting of the suicide of a celebrity on suicide rates: A population-based study. International Journal of Epidemiology, 36, 1229-1234. http://dx.doi.org/10.1093/ije/dym196

Clark, K., Brass, G., Rowe, T., \& Menzies, C. (2003). EXTRA! EXTRA! Public education chokes on cup of campbell's soup. Retrieved from http://faculty.arts.ubc.ca/menzies/documents/ANTH516_Media. pdf

Crasborn, F., Hennissen, P., Brouwer, N., Korthagen, F., \& Bergen, T. (2011). Exploring a two-dimensional model of mentor teacher roles in mentoring dialogues. Teacher and Teacher Education, 27, 320-331. http://dx.doi.org/10.1016/j.tate.2010.08.014

Denzin, N. K., \& Lincoln, Y. S. (2013). Introduction: The discipline and practice of qualitative research. In Denzin \& Lincoln (Eds.), The SAGE Handbook of Qualitative Research (4th ed., pp. 1-32). Thousand Oaks CA: SAGE.

Devereux, E. (2003). Understanding the media. London: Sage.

Dixon-Krauss, L. A. (1995). Partner reading and writing: Peer social dialogue and the zone of proximal development. Journal of Reading Behavior, 27(10), 45-63.

Ekşi, G. Y. (2013). E-dialogue journal: Student teachers' perspectives on their school experience. Procedia-Social and Behavioral Sciences, 70, 1810-1819. http://dx.doi.org/10.1016/j.sbspro.2013.01.257

Gillespie, A. (2007). The social basis of self-reflection. In J. Valsiner, \& A. Rosa (Eds.), The Cambridge handbook of sociocultural psychology (pp. 678-691). Cambridge: Cambridge University Press. http://dx.doi.org/10.1017/CBO9780511611162.037

Gregory, J., \& Miller, S. (1998). Science in public: Communication, culture, and credibility. New York: Plenum.

Hatton, N., \& Smith, D. (1995). Reflection in teacher education towards definition and implementation. Teaching \& Teacher Education, 11, 33-49. http://dx.doi.org/10.1016/0742-051X(94)00012-U

Hermann, M. G., \& Woyach, R. B. (1994). Toward reflection, evaluation, and integration in international studies: An editorial philosophy. Mershon International Studies Review, 38(1), 1-10. http://dx.doi.org/10.2307/222608

Keeble, R. (2001). The newspaper handbook (3rd ed.). London: Routledge.

Kim, H. S., Bigman, C. A., Leader, A., Lerman, C., \& Cappella, J. N. (2012). Narrative health communication and behavior change: The influence of exemplars in the news on intention to quit smoking. Journal of Communication, 62(3), 473-492. http://dx.doi.org/10.1111/j.1460-2466.2012.01644.x

Lesley, M., Watson, P., \& Elliot, S. (2007). "School" reading and multiple texts: Examining the metacognitive development of secondary-level student teachers. Journal of Adolescent \& Adult Literacy, 51, 150-162. http://dx.doi.org/10.1598/JAAL.51.2.6

Lincoln, Y. S., \& Guba, E. G. (1985). Naturalistic inquiry. Sage, Beverly Hills, CA.

Liu, S.-H. (2011). Factors related to pedagogical beliefs of teachers and technology integration. Computers \& Education, 56(4), 1012-1022. http://dx.doi.org/10.1016/j.compedu.2010.12.001

Liu, S.-H., \& Tsao, S.-C., (2013). How did the meanings constructed by Taiwanese student teachers from educational news media affect their beliefs? Educational Media International, 50(2), 135-147.

Lu, C. H. (2010). How national newspapers frame the image of southern Taiwan? Journal of Southern Taiwan University, 35(4), 81-106.

Manouchehri, A. (2002). Developing teaching knowledge through peer discourse. Teaching and Teacher Education, 18, 715-737. http://dx.doi.org/10.1016/S0742-051X(02)00030-6

McBride, R. E., Xiang, R., Wittenburg, D., \& Shen, J. (2002). An analysis of preservice teachers' disposition 
toward critical thinking: A cross-cultural perspective. Asia-Pacific Journal of Teacher Education, 30(2), 131-140. http://dx.doi.org/10.1080/13598660220135649

McCombs, M., \& Reynolds, A. (2002). News influence on our picture of the world. In J. Bryant, \& D. Zillmann (Eds.), Media effects: Advances in theory and research (2nd ed., pp. 1-18). Mahwah, NJ: Lawrence Erlbaum Associates.

McKane, A. (2006). Newswriting. London: Sage.

McMahon, S. I. (1997). Using documented written and oral dialogue to understand and challenge student teachers' reflections. Teaching and Teacher Education, 13(2), 199-213. http://dx.doi.org/10.1016/S0742-051X(96)00016-9

Nakamura, M. (2004). Ideology in the news: A critical discourse analysis of news reporting in Taiwan's two newspapers (Unpublished master thesis). National Tsing Hua University, Taiwan.

O'Callaghan, C. (2001). Social construction of student teachers' instructional strategies for reading. The Teacher Educator, 36, 265-281. http://dx.doi.org/10.1080/08878730109555271

Okan, Z., \& Yildırım, R. (2004). Some reflections on learning from early school experience. International Journal of Educational Development, 24(6), 603-616. http://dx.doi.org/10.1016/j.ijedudev.2004.02.004

Oroujlou, N. (2012). Subliminal ideology in media: Representation of Iran's nuclear energy in American networks and newspapers. Procedia-Social and Behavioral Sciences, 51, 38-42. http://dx.doi.org/10.1016/j.sbspro.2012.08.115

Pedro, J. Y. (2005). Reflection in teacher education: Exploring preservice teachers' meanings of reflective practice. Reflective Practice: International and Multidisciplinary Perspectives, 6(1), 49-66. http://dx.doi.org/10.1080/1462394042000326860

Postholm, M. B. (2008). Cultural historical activity theory and Dewey's idea-based social constructivism: Consequences for educational research. Critical Social Studies, 1, 37-48.

Pressley, M. G. (2006). Reading instruction that works: The case for balanced teaching (3rd ed.). New York, NY: The Guilford Press.

Rabikowska, M. (2008). The paradoxical position of self-reflection in teaching and assessment in higher education: How the application of blogging challenges learning habits. The International Journal of Learning, 15(7), 1-12.

Ross, K., \& Nightingale, V. (2003). Media and audiences. Maidenhead: Open University Press.

Rushton, S. P. (2003). Two preservice teachers' growth in self-efficacy while teaching in an inner-city school. Urban Review, 35(3), 167-189. http://dx.doi.org/10.1023/A:1025788102188

Stump, S. L. (2010). Reflective tutoring: Insights into preservice teacher learning. School Science \& Mathematics, 110(1), 47-54. http://dx.doi.org/10.1111/j.1949-8594.2009.00006.x

Tillema, H. H. (2000). Belief change towards self-directed learning in student teachers: Immersion in practice or reflection on action. Teaching and Teacher Education, 16(5-6), 575-591. http://dx.doi.org/10.1016/S0742-051X(00)00016-0

Tsaganou, G., \& Grigoriadou, M. (2011). Authoring with Retudisauth adaptive dialogues for text comprehension. Procedia-Social and Behavioral Sciences, 15, 2813-2817. http://dx.doi.org/10.1016/j.sbspro.2011.04.194

van Eekelen, I. M., Boshuizen, H. P. A., \& Vermunt, J. D. (2005). Self-regulation in higher education teacher learning. Higher Education, 50, 447-471. http://dx.doi.org/10.1007/s10734-004-6362-0

Vygotsky, L. (1978). Mind in society: The development of higher psychological processes. Cambridge, MA: Harvard University Press.

Wade, R., \& Yarbrough, D. (1996). Portfolios: A tool for reflective thinking in teacher education? Teaching and Teacher Education, 12(1), 63-79. http://dx.doi.org/10.1016/0742-051X(95)00022-C

Zillmann, D., \& Brosius, H.-B. (2000). Exemplification in communication: The influence of case reports on the perception of issues. Mahwah, NJ: Erlbaum. 


\section{Copyrights}

Copyright for this article is retained by the author(s), with first publication rights granted to the journal.

This is an open-access article distributed under the terms and conditions of the Creative Commons Attribution license (http://creativecommons.org/licenses/by/3.0/). 